\title{
The Influence of Rolling Conditions on Deformation Behavior of Magnesium Alloy Sheets
}

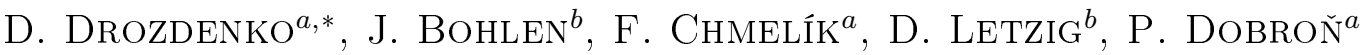 \\ ${ }^{a}$ Charles University in Prague, Department of Physics of Materials, Ke Karlovu 5, 12116, Prague 2, Czech Republic \\ ${ }^{b}$ Helmholtz-Zentrum Geesthacht, Zentrum für Material- und Küstenforschung GmbH, \\ Max-Planck-Str. 1, D21502 Geesthacht, Germany
}

\begin{abstract}
The influence of texture on deformation behavior was investigated for conventionally rolled magnesium alloy slabs and rolled twin roll cast magnesium alloy strips in the form of sheets. The $\mathrm{Mg}-\mathrm{Zn}$ based sheets were deformed at room temperature with the tensile axis oriented in the rolling and transversal directions. The texture with respect to different rolling conditions was characterized by X-ray diffraction. In the case of $\mathrm{Mg}-\mathrm{Zn}-\mathrm{rare}$ earth alloy sheets, the basal pole intensity, aligned with the sheet normal direction, is lower for conventionally rolled sheet in comparison to the rolled twin roll cast strip. Difference in angular distribution of basal planes influences on the mechanical behavior of the sheets. The yield strength is higher for the tension along rolling direction than along transversal direction for the conventionally rolled sheets, whereas the opposite deformation behavior is observed for the rolled twin roll cast strips. Furthermore, the planar anisotropy of the yield strength is less pronounced for the rolled twin roll cast strips. The deformation behavior of the sheets was also investigated by the acoustic emission technique. The acoustic emission signal analysis correlates the microstructure and the stress-time curves with active deformation mechanisms. It highlights the activity of a basal slip and tensile twinning, particularly during the transverse direction tension.
\end{abstract}

DOI: 10.12693 /APhysPolA.128.795

PACS: 81.70.Bt, 81.20.Wk, 61.72.Mm, 61.72.Hh, 43.40.Le

\section{Introduction}

Magnesium alloys are used in many technical applications, such as aircraft and automotive industry, due to their low density and high damping capacity. Recent development for industrial applications is focused on the utilization of magnesium sheets.

A limiting factor for their wide use is a lack of initially active deformation modes at room temperature (RT). Magnesium with a hexagonal close packed (hcp) lattice exhibits a distinct difference in the critical resolved shear stress (CRSS) for individual slip and twinning systems $[1,2]$.

It is generally accepted that plastic deformation in $\mathrm{Mg}$ alloy sheets is initially realized by dislocation glide in basal planes which is subsequently accompanied by a contribution of dislocation glide in non-basal planes and/or twinning. Hama and Takuda [3] claimed that the activity of the basal slip systems depends on the inhomogeneity of the materials. In addition, homogeneous deformation is possible only when the second-order pyramidal slip systems are active, i.e. the glide of $\langle c+a\rangle)$ dislocations plays an important role [4-7].

Rolled sheets of the Mg-based alloys exhibit a specific basal texture, where the orientation of basal planes is almost parallel to the sheet plane [8-10]. Such a texture

\footnotetext{
* corresponding author; e-mail: drozdenko@karlov.mff.cuni.cz
}

favors deformation twinning if compressive stress is applied along the rolling direction (RD) [11]. For detailed analysis of twin activity in $\mathrm{Mg}$ alloys electron backscatter diffraction (EBSD) method is used [12]. Moreover, the orientation distribution of basal planes around normal direction (ND) is wider in the $\mathrm{RD}$ than in the transversal direction (TD) for AZ31 magnesium alloy [13]. Bohlen et al. [12, 14] have recently reported that the angular distribution of the basal planes in the magnesium-zincrare earth (RE) alloy sheets is significantly wider in the TD than in the RD. The analysis of the texture development in Mg-based alloys sheets shows that RE elements additions significantly influence the final rolling texture and consequently affect the deformation behavior and mechanical properties $[10,14-17]$. The final texture of rolled magnesium alloy sheets can be also influenced by annealing and/or recrystallization [18-20].

In general, the initial deformation texture is responsible for the planar anisotropy of mechanical properties in wrought $\mathrm{Mg}$ alloys. Yield strength (YS) and ultimate tensile strength (UTS) show a distinct orientation dependence in AZ31, being lower in the RD than in the TD [13].

The AE technique can be used to obtain information about the dislocation dynamic and a twin nucleation. AE is defined as a transient elastic wave, which is generated by the rapid release of energy within a material due to sudden localized structure changes [21]. Application of the $\mathrm{AE}$ technique for the investigation of deformation mechanisms in $\mathrm{Mg}$ alloys can be found in [22-26]. For example, the influence of the sample orientation on acoustic 
emission (AE) during tensile tests of $\mathrm{Mg}-\mathrm{Zn}-\mathrm{RE}$ alloys was discussed by Bohlen et al. [14].

The objective of the present work is to analyze the influence of rolling process, represented by the initial texture, on the deformation behavior. The stress vs. time dependence was used to investigate deformation mechanisms during tensile loading. The AE activity, represented in terms of the $\mathrm{AE}$ count rate and the peak amplitude of the AE events, helps to reveal dislocation dynamics and twin nucleation during plastic deformation.

\section{Experimental}

AZ31 $(\mathrm{Mg}+3 \mathrm{wt} \% \mathrm{Al}+1 \mathrm{wt} \% \mathrm{Zn})$ and $\mathrm{ZE10}(\mathrm{Mg}+$ $1.3 \mathrm{wt} \% \mathrm{Zn}+0.2 \mathrm{wt} \% \mathrm{Ce}+0.1 \mathrm{wt} \% \mathrm{La})$ magnesium alloys were prepared in the shape of slabs and twin roll cast (TRC) strips. They were subsequently subjected to conventional rolling into sheets of the thickness of $1.5 \mathrm{~mm}$. Hereafter experimental materials are denoted as the rolled AZ31 (ZE10) and the rolled AZ31 (ZE10) TRC strips. Samples for tensile tests were machined with loading axis in RD and TD with the gauge length and width of $35 \mathrm{~mm}$ and $6 \mathrm{~mm}$, respectively. The specimens were deformed in a universal testing machine Zwick Z50 at the RT and at a constant strain rate of $10^{-3} \mathrm{~s}^{-1}$.

The texture of the alloys was determined prior to deformation. The X-ray PANalytical XPert diffractometer using $\mathrm{Cu} K_{\alpha}$ radiation was used to construct pole figures of polished samples in reflection geometry to the sample tilt of $70^{\circ}$.

A computer controlled PCI-2 (Physical Acoustic Corporation) device was used to monitor the AE activity, which is based on continuous storage of preamplified AE signals ( $40 \mathrm{~dB}$ ) with $2 \mathrm{MHz}$ sampling frequency. The full scale of the A/D converter was $\pm 10 \mathrm{~V}$. A sensor (miniaturized MST8S piezoelectric transducer with the diameter of $3 \mathrm{~mm}$ and a flat response in a frequency band from 100 to $600 \mathrm{kHz}$ ) was attached to the specimen surface using a silicon grease and a spring. The AE analysis is based on a threshold level detection, which is used to get a comprehensive set of AE parameters. The threshold level was set to $26 \mathrm{~dB}$ to avoid any influence of the background noise. The dead time for the separation of individual $\mathrm{AE}$ events was set to $50 \mu \mathrm{s}$. The AE count rate $\Delta N_{C} / \Delta t$ (the count number per time unit [27] at a given threshold voltage level) and the peak amplitude of events provide information about the dislocation slip dynamic and the nucleation of twins.

\section{Experimental results}

The initial textures of the alloys after rolling are represented by the distribution of basal (0002) and prismatic (10-10) poles (Fig. 1). The pole figures of AZ31 sheets in both rolling conditions (the conventionally rolled slab and the rolled sheet of TRC strip) display basal character of the texture with a significant concentration of basal planes oriented into ND (basal planes are parallel to the

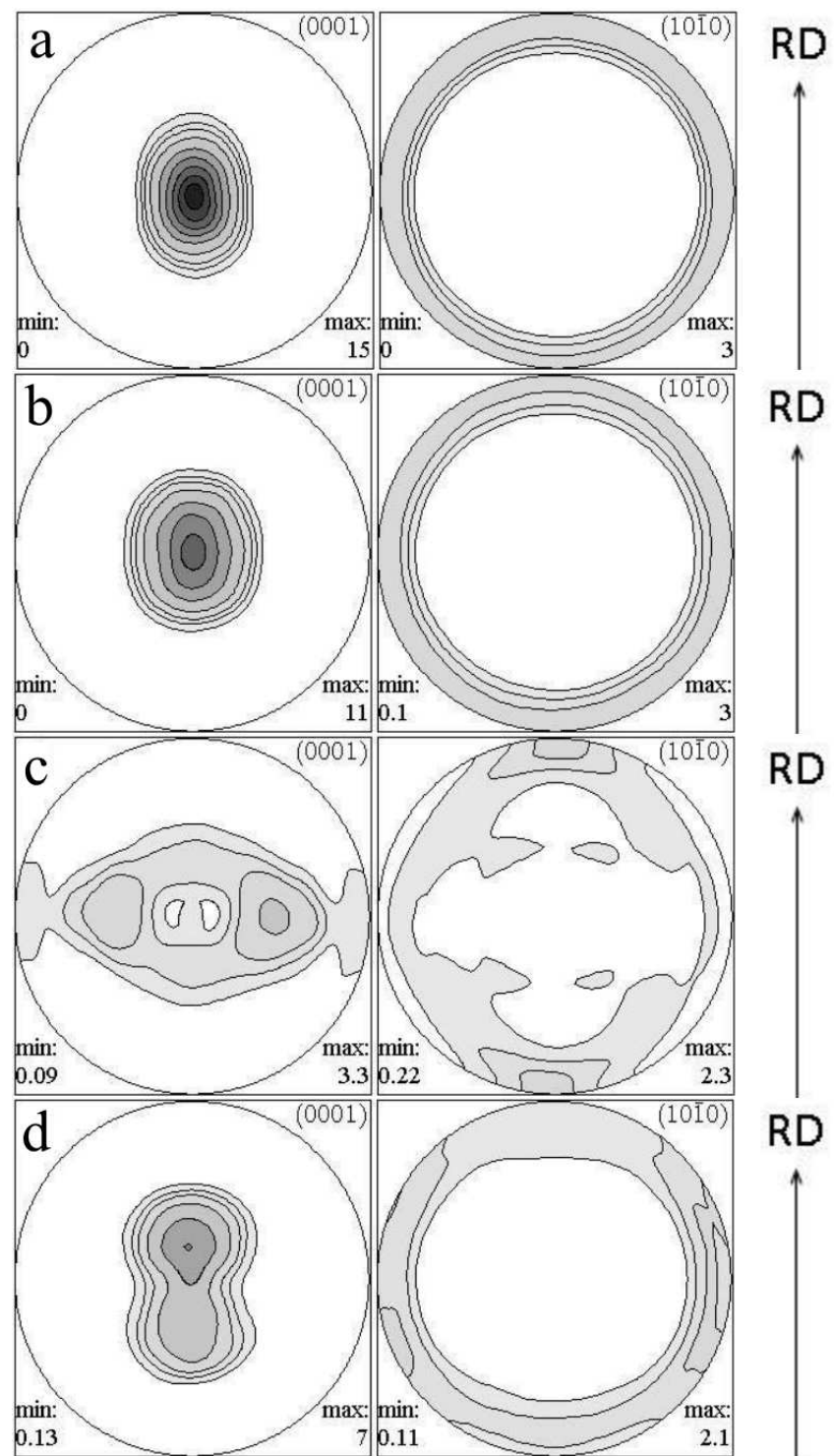

Fig. 1. Initial texture of $\mathrm{Mg}$ alloys: (a) rolled AZ31, (b) rolled AZ31 TRC strip, (c) rolled ZE10, (d) rolled ZE10 TRC strip.

sheet plane). The orientation distribution of the basal planes around the ND is wider in the RD than in the TD. The intensity of the basal pole of the rolled AZ31 TRC strip is lower than that of the rolled AZ31.The intensities of the (0002) and (10-10) pole figures for $\mathrm{Mg}$ alloy with RE alloying elements in both rolling conditions are significantly lower than that for AZ31 Mg alloy. The intensity peak of basal pole figure for the rolled ZE10 is tilted away from the sheet ND toward TD and is split into two peaks (see Fig. 1c).

The pole distribution of the basal planes for rolled ZE10 TRC strip is different from that, which is usually observed in the $\mathrm{Mg}$ alloys with RE alloying elements [14]. The texture could be defined as a texture with essentially basal character and basal planes are slightly tilted toward 
the RD. The intensity of the basal pole is higher for the rolled ZE10 TRC strip than for the rolled ZE10, and lower than that for the rolled AZ31 TRC strip.

Intensity distribution of (10-10) pole figures for both AZ31 sheets is homogeneous in contrast to the ZE10 sheets. In rolled ZE10, the prismatic pole has two peaks toward the RD, and in the rolled ZE10 TRC strip the higher intensity of (10-10) pole figure is observed toward the TD.

Mechanical properties of rolled Mg alloys: TYS - tensile yield strength, UTS - ultimate tensile

TABLE strength.

\begin{tabular}{c|c|c|c|c|c|c|c|c}
\hline \hline Alloy & \multicolumn{2}{|c|}{ Rolled AZ31 } & \multicolumn{2}{c|}{ Rolled AZ31 TRC strip } & \multicolumn{2}{c|}{ Rolled ZE10 } & \multicolumn{2}{c}{ Rolled ZE10 TRC strip } \\
\hline loading direction & RD & TD & RD & TD & RD & TD & RD & TD \\
\hline TYS [MPa] & $149 \pm 2$ & $196 \pm 1$ & $194 \pm 1$ & $205 \pm 1$ & $172 \pm 3$ & $103 \pm 3$ & $140 \pm 1$ & $166 \pm 3$ \\
UTS [MPa] & $263 \pm 1$ & $266 \pm 1$ & $281 \pm 1$ & $281 \pm 1$ & $234 \pm 1$ & $218 \pm 1$ & $223 \pm 0.5$ & $231 \pm 0.5$ \\
Uniform elongation [\%] & $15.8 \pm 0.2$ & $13.2 \pm 0.1$ & $15.3 \pm 2$ & $13.7 \pm 1$ & $11.4 \pm 1$ & $19.6 \pm 2$ & $16.8 \pm 2$ & $14.5 \pm 3$ \\
Fracture strain [\%] & $24.1 \pm 0.5$ & $24.6 \pm 0.5$ & $20.5 \pm 0.5$ & $19.3 \pm 0.5$ & $24.8 \pm 0.5$ & $29.5 \pm 1$ & $29.5 \pm 1$ & $27.5 \pm 1.5$
\end{tabular}

From the inspection of the stress-strain curves, it is obvious that the rolling conditions have a strong influence on the deformation behavior (Figs. 2-5). The shape of the stress-strain curves is typical for the rolled $\mathrm{Mg}$ alloys and their characteristic values are presented in the Table. It can be seen that for the rolled ZE10 the higher value of the YS is observed for the RD sample than that for the TD sample. In case of the rolled ZE10 TRC strip the YS is higher for the TD sample than for the RD sample. Both rolled AZ31 and rolled AZ31 TRC strip exhibit the higher YS for the TD sample than for the RD sample. It is noteworthy that value of the YS for the rolled AZ31 TRC strip is significantly higher than that for the rolled ZE10 TRC strip.

Therefore, all four $\mathrm{Mg}$ alloys exhibit the strong planar anisotropy of the YS. The planar anisotropy of the YS is less pronounced for the rolled TRC strips of both $\mathrm{Mg}$ alloys than for the conventionally rolled sheets (see the Table). For the rolled ZE10 sheet the planar YS anisotropy is more pronounced than for other sheets and it almost disappears for the rolled AZ31 TRC strip.

Significant difference in the AE response is observed during testing the sheets in both rolling conditions. Figures 2,3 show the stress vs. time curves with the corresponding AE response for the tensile loading in the RD and the TD for rolled AZ31 and for rolled AZ31 TRC strip. The analogous data of tensile tests for ZE10 Mg alloy are presented in Figs. 4, 5 .

The AE count rate exhibits a maximum at the beginning of plastic deformation in all samples, which is followed by a decrease in the AE count rate persisting until the end of the deformation test. Furthermore, in rolled ZE10 the AE count rate exhibits two maxima close to the macroscopic yield point (see Fig. 5a).

It is important to note that the difference in the $\mathrm{AE}$ activity is observed during straining along various directions of rolled AZ31 (and ZE10) magnesium alloys (see Figs. 2, 3, and 4, 5, respectively). During the tensile

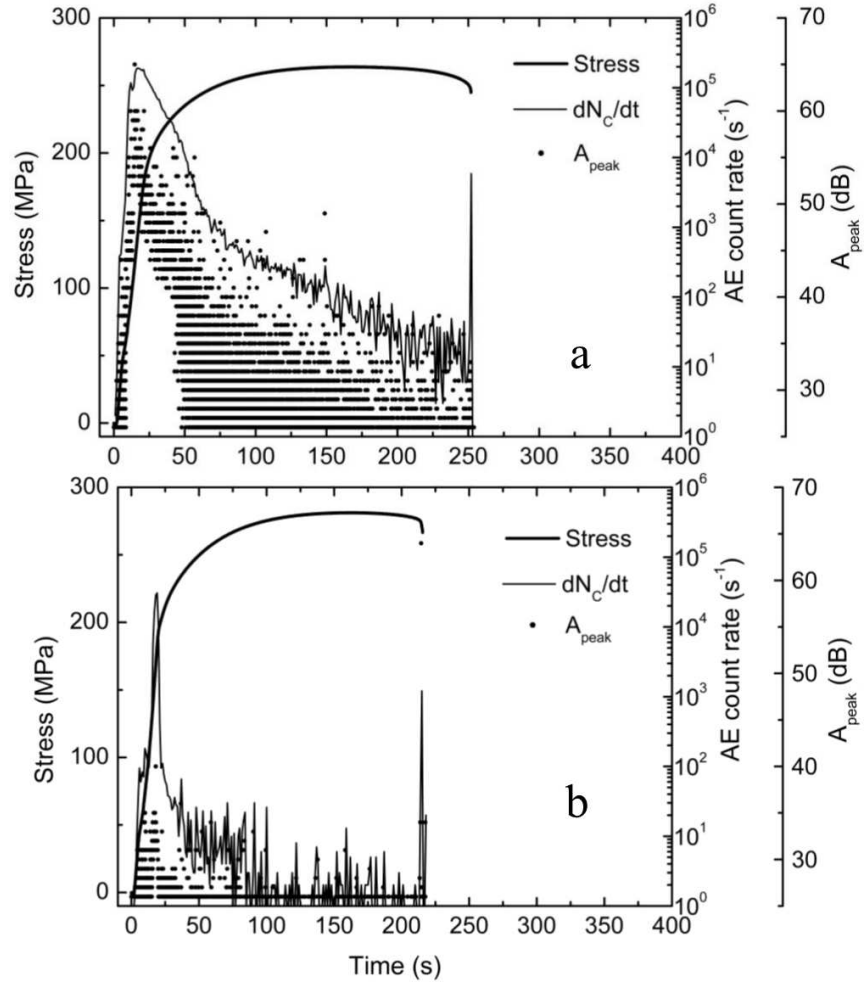

Fig. 2. Stress vs. time curves with the corresponding $\mathrm{AE}$ response (AE count rate, peak amplitudes of $\mathrm{AE}$ events) of tension along RD for (a) the rolled AZ31 and (b) the rolled AZ31 TRC strip.

loading of the AZ31 Mg alloy in the RD, the AE activity is higher in conventionally rolled sheets than in the rolled TRC strips. If tensile loading is applied along the TD, the AE activity is higher in rolled AZ31 TRC strip than in rolled AZ31. For $\mathrm{Mg}$ alloy with RE alloying elements the higher AE activity during TD loading is observed in rolled ZE10. 


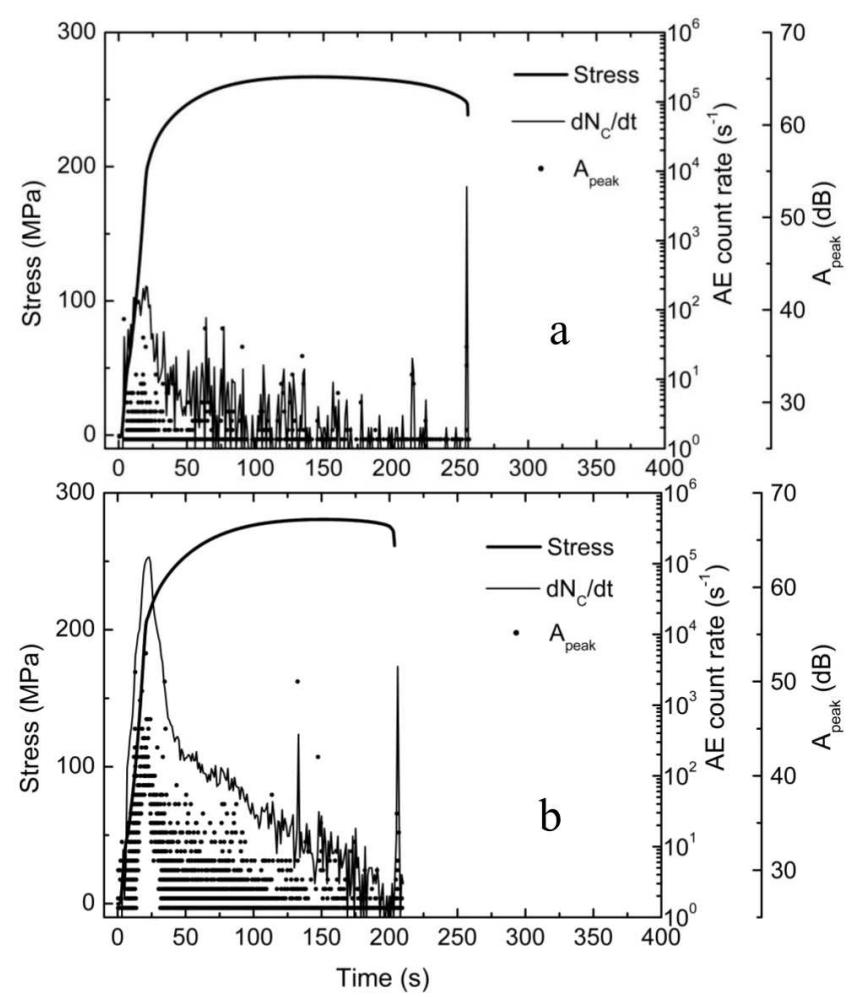

Fig. 3. Stress vs. time curves with the corresponding $\mathrm{AE}$ response (AE count rate, peak amplitudes of $\mathrm{AE}$ events) of tension along TD for (a) the rolled AZ31 and (b) the rolled AZ31 TRC strip.

The decrease of the AE count rate after the macroscopic yield point during RD loading of the rolled ZE10 is rapid, while it is more gradual for the rolled ZE10 TRC strip (Fig. 4).

\section{Discussion}

The significant difference in the texture of $\mathrm{Mg}$ alloys after applying of the different rolling conditions can be seen in Fig. 1. Weakening of the texture due to an addition of the RE alloying elements is observed for both rolled ZE10 and rolled ZE10 TRC strip. Similar weak non-basal texture, with the angular spread of basal planes towards the $\mathrm{TD}$, in rolled and annealed $\mathrm{Mg}-1 \mathrm{Zn}-0.3 \mathrm{Ce}$ alloy was presented by Mackenzie and Pekguleryuz [8]. The different orientation of the basal pole peak for rolled ZE10 TRC strip is caused by the conventional rolling after the TRC process.

The difference in the texture of materials is responsible for the anisotropy of mechanical properties. It clearly seen that in sheet plane the higher the angular distribution of the basal planes, the more pronounced anisotropy of the YS is observed (Fig. 1, the Table).

The strengthening of the AZ31 Mg alloy is higher in the TD than in the RD for both rolling conditions. This behavior was also observed by Agnew and Duygulu [6] and could be explained by the influence of the initial texture

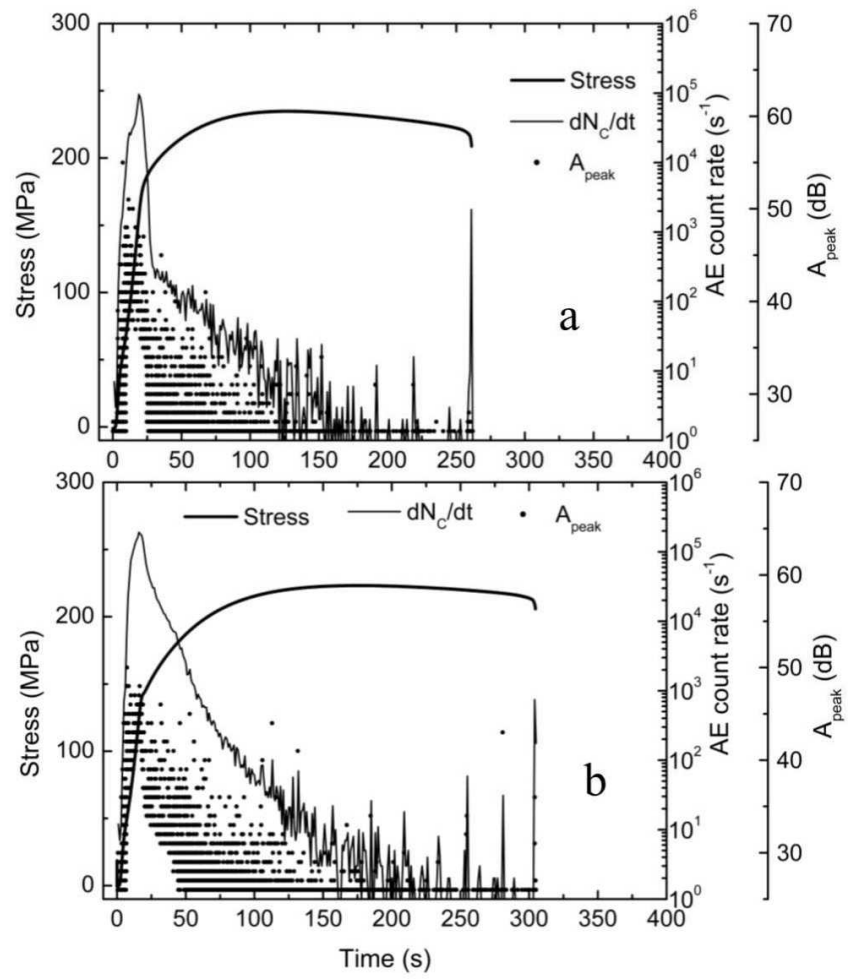

Fig. 4. Stress vs. time curves with the corresponding $\mathrm{AE}$ response (AE count rate, peak amplitudes of $\mathrm{AE}$ events) of tension along RD for (a) the rolled ZE10 and (b) the rolled ZE10 TRC strip.

of materials. The prismatic plane poles in AZ31 Mg alloys have no orientation preference in the sheet plane and therefore, the difference in the orientation of the basal planes significantly influences deformation behavior. Angular spread of basal planes toward RD gives opportunity for activation of non-basal slip and/or twinning system during RD loading at lower stress [28]. During tension along TD, basal planes are oriented parallel to loading axis. In this case, activation of non-basal slip and twinning system requests higher stress, and therefore, work hardening is stronger.

Rolled ZE10 TRC strip with the angular distribution of basal planes similar to AZ31 Mg alloys exhibits a similar anisotropy consisting of a higher level of strength in the TD compared to the RD. For the rolled ZE10, however, an inverse anisotropy is observed: the YS in the RD appears to be higher than that in the TD, which is caused by characteristic inverse angular spread of basal planes: toward TD. The planar anisotropy of the YS of the ZE10 sheets was also discussed in [12], where the complex study of deformation curves, concurrent AE measurements and work hardening analysis (the Kocks-Mecking plots) were presented.

The characteristic maximum of the $\mathrm{AE}$ count rate, which is observed at the beginning of the plastic deformation, is usually explained by a massive dislocation 


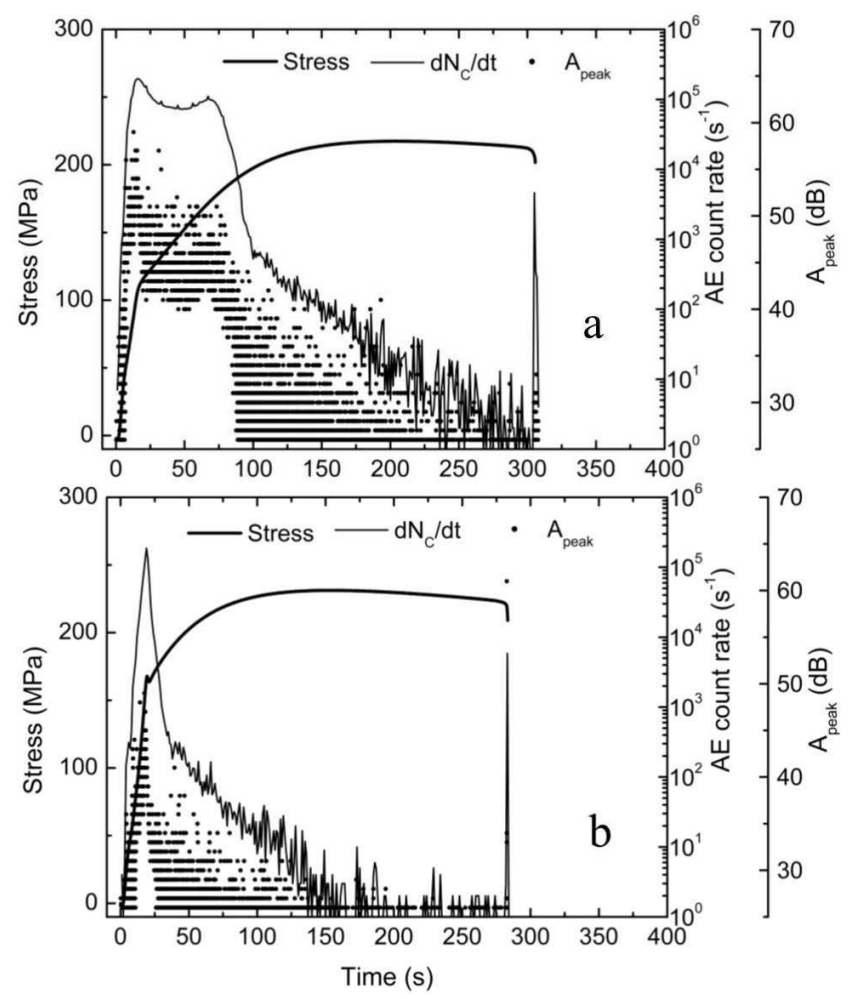

Fig. 5. Stress vs. time curves with the corresponding $\mathrm{AE}$ response (AE count rate, peak amplitudes of $\mathrm{AE}$ events) of tension along TD for (a) the rolled ZE10 and (b) the rolled ZE10 TRC strip.

multiplication, whereby various slip systems can be activated [21]. In Mg alloys, the basal slip is known as the easiest activated slip (the lowest value of CRSS in comparison with other slip systems at RT) [29] and therefore, basal slip is taken as a first activated mechanism in $\mathrm{Mg}$ alloys. During this process collective dislocation motion releases some amount of energy in the material, which is detected as a strong AE signal [21]. Then plastic deformation in $\mathrm{Mg}$ alloys proceeds by non-basal slip (e.g. prismatic $\langle a\rangle$, pyramidal $\langle c+a\rangle)$ and twinning. Theoretically the different micromechanisms of the plastic deformation produce different waveforms of AE signal [21] which consequently could be separated by various $\mathrm{AE}$ parameters (e.g. AE event). It is generally accepted that the twin nucleation is a excellent source of the AE signal and is characterized by burst type of AE signal [21, 30].

As we can see in Figs. 1-5, the difference in the AE response during tension of the sheets along various directions is associated with differences in the texture of materials. During RD loading of the rolled AZ31, which has the basal texture with wider distribution of basal planes toward RD and the high intensity of pole, the AE signal is higher. Whereas, the rolled AZ31 TRC strip with more symmetric spread of basal pole in sheet plane, and lower intensity exhibits lower AE activity during the same tensile loading. Difference in the AE response could be explained by various combination of activity of prismatic $\langle a\rangle$ and pyramidal $\langle c+a\rangle$ slip and twinning system with respect to angular distribution of basal planes. In works of Dobron et al. [12] it was concluded that the tensile twins may occur in a grain only, if the $c$-axis and the tensile axis are sufficiently close to each other. Thus it could be supposed that during RD loading probability of twin activation in rolled AZ31 is higher than that in rolled AZ31 TRC strip. Likewise, lower AE response in rolled AZ31 during TD loading than during RD loading is explained by lower probability of twin activation (Fig. 1a, 2a, 3a).

Almost no orientation preference of basal planes in sheet plane in rolled AZ31 TRC strip (Fig. 1b) is responsible for similar passing of plastic deformation during $\mathrm{RD}$ and TD loading, therefore, similar AE response is seen in Figs. 2b, 3b.

The difference in orientation preferences of crystallographic planes in rolled ZE10 and rolled ZE10 TRC strips, as well as in AZ31, is reflected in the AE response during tension of the sheets especially along the TD (Fig. 1c, d and 5). The basal poles of rolled ZE10 are tilted by $45^{\circ}$ along the TD (Fig. 1c), which gives opportunity for twinning activity. Therefore, the second maximum of the AE count rate and relatively high values of peak amplitude of events (Fig. 5a) could be explained as a twinning activity. This suggestion is supported by the typical S-shape of the deformation curve. The activity of tensile twins during TD loading of ZE10 sheet with the similar texture was studied by AE, EBSD techniques in works of Dobron et al. [12].

The subsequent rapid decrease of the $\mathrm{AE}$ count rate after the yield point during RD loading of rolled ZE10 is associated with activation of non-basal slip systems and increasing number of sessile dislocations. Sessile dislocations reduce the free path of moving dislocations consequently. This suggestion correlates with stronger hardening for rolled ZE10 comparing with rolled ZE10 TRC, see Fig. 4.

\section{Conclusions}

The texture analysis and in situ AE measurements during tensile tests were used for investigation of the effect of the rolling procedure on the deformation behavior of $\mathrm{Mg}$ alloys. Both rolled AZ31 $\mathrm{Mg}$ alloys exhibit a typically basal texture. In the case of $\mathrm{Mg}-\mathrm{Zn}-$ rare earth alloy sheet, two different types of texture with respect to rolling conditions were observed.

Deformation during the loading along the TD of conventionally rolled sheet ZE10 is realized by basal slip and deformation twinning, which is supported by the AE measurement. The double maximum of the AE count rate near the macroscopic yield point confirms twinning activity.

We can see that anisotropy of mechanical properties may be easily connected with the texture asymmetry around the ND, which is formed during rolling process. 
Effect of the rolling conditions on the texture of materials is well seen in the AE response during tensile loading of both Mg alloys. Rolled AZ31 TRC strip exhibits similar AE response during TD and RD loading due to least pronounced anisotropy of the YS. While in rolled ZE10 there is a difference in AE response with respect to orientation of crystallographic planes. The higher the angular distribution of the basal planes toward loading axis, the higher AE response is observed.

\section{Acknowledgments}

This work received support by the Czech Science Foundation under the grant 13-19812S, by the Grant Agency of Charles University under grant 1882314 and also by the grant SVV-2015-260213. The work of P.D. is a part of activities of the Charles University Research Center "Physics of Condensed Matter and Functional Materials".

\section{References}

[1] S. Ando, H. Tonda, Mater. Sci. Forum 350-351, 43 (2000).

[2] A. Staroselsky, L. Anand, Int. J. Plasticity 19, 1843 (2003).

[3] T. Hama, H. Takuda, Int. J. Plasticity 27, 1072 (2011).

[4] F.F. Lavrentev, Mater. Sci. Eng. A 46, 191 (1980).

[5] P. Lukáč, Czech. J. Phys. B 35, 275 (1985).

[6] S.R. Agnew, O. Duygulu, Int. J. Plasticity 21, 1161 (2005).

[7] S. Sandlöbes, S. Zaeffere, I. Schestakow, S. Yi, R. Gonzalez-Martinez, Acta Mater. 59, 429 (2011).

[8] L.W.F. Mackenzie, M.O. Pekguleryuz, Scr. Mater. 59, 665 (2008).

[9] S.B. Yi, J. Bohlen, F. Heinemann, D. Letzig, Acta Mater. 58, 592 (2010).

[10] K. Hantzsche, J. Bohlen, J. Wendt, K.U. Kainer, S.B. Yi, D. Letzig, Scr. Mater. 63, 725 (2010).

[11] R.E. Reed-Hill, Role of deformation twinning in determining the mechanical properties of metals: the inhomogeneity of plastic deformation, ASM International, Materials Park 1973, p. 285.

[12] P. Dobroň, J. Balík, F. Chmelík, K. Illková, J. Bohlen, D. Letzig, J. Alloy Comp. 588, 628 (2014).
[13] J. Bohlen, F. Chmelík, P. Dobroň, D. Letzig, F. Kaiser, P. Lukáč, K.U. Kainer, J. Alloy Comp. 378, 207 (2004).

[14] J. Bohlen, M.R. Nürnberg, J.W. Senn, D. Letzig, S.R. Agnew, Acta Mater. 55, 2101 (2007).

[15] C. Xu, S.W. Xu, M.Y. Zheng, K. Wu, E.D. Wang, S. Kamado, G.J. Wang, X.Y. Lv, J. Alloys Comp. 524, 46 (2012).

[16] T. Itoi, T. Inazawa, M. Yamasaki, Y. Kawamura, M. Hirohashi, Mater. Sci. Eng. A 560, 216 (2013).

[17] C.J. Bettles, M.A. Gibson, J. Min. Met. Mat. S. 57, 46 (2005).

[18] T. Wu, L. Jin, W.X. Wu, L. Gao, J. Wang, Z.Y. Zhang, J. Dong, Mater. Sci. Eng. A 584, 97 (2013).

[19] J. Sun, L. Jin, S. Dong, Z. Zhang, J. Dong, Mater. Lett. 107, 197 (2013).

[20] H. Kang, D.H. Bae, Mater. Sci. Eng. A 582, 203 (2013).

[21] C.R. Heiple, S.H. Carpenter, J. Acoust. Emission 6, 177 (1987).

[22] P. Dobroň, J. Bohlen, F. Chmelík, P. Lukáč, D. Letzig, K.U. Kainer, Mater. Sci. Eng. A 462, 307 (2007).

[23] F. Chmelík, F.B. Klose, H. Dierke, J. Šachl, H. Neuhäuser, P. Lukáč, Mater. Sci. Eng. A 462, 53 (2007).

[24] P. Dobroň, J. Bohlen, F. Chmelík, P. Lukáč, D. Letzig, K.U. Kainer, Kovove Mater. 45, 129 (2007).

[25] A. Vinogradov, D. Orlov, A. Danyuk, Y. Estrin, 10.1016/j.actamat.2012.12.024Acta Mater. 61, 2044 (2013).

[26] M. Janeček, R. Král, P. Dobroň, F. Chmelík, V. Šupík, F. Holländer, Mater. Sci. Eng. A 462, 311 (2007).

[27] Standard Practice for Acoustic Emission Examination of Fiberglass Reinforced Plastic Resin, ASTM E 1067-85. Tank/Vessels, 1985.

[28] S.R. Agnew, O. Duygulu, Mater. Sci. Forum 419422, 177 (2003).

[29] P.W. Bakarian, C.H. Mathewson, Trans. AIME, 152, 226 (1943).

[30] T. Richeton, P. Dobron, F. Chmelik, J. Weiss, F. Louchet, Mater. Sci. Eng. A 424, 190 (2006). 